\title{
Neural correlates of attitude change following positive and negative advertisements
}

\author{
Junko Kato ${ }^{1 * \dagger}$, Hiroko Ide ${ }^{1+}$, Ikuo Kabashima', Hiroshi Kadota ${ }^{2}$, Kouji Takano $^{2}$ and Kenji Kansaku ${ }^{2 *}$ \\ 1 Graduate School of Law and Politics, The University of Tokyo, Bunkyo, Tokyo, Japan \\ 2 Cognitive Functions Section, Department of Rehabilitation for Sensory Functions, Research Institute of National Rehabilitation Center for Persons with Disabilities, \\ Tokorozawa, Saitama, Japan
}

\section{Edited by:}

Daeyeol Lee, Yale University, School of

Medicine, USA

\section{Reviewed by:}

Ming Hsu, University of Illinois at

Urbana, Champaign, USA

Daeyeol Lee, Yale University, School of

Medicine, USA

*Correspondence:

Dr. Junko Kato, The University of Tokyo, Graduate School of Law and Politics,

7-3-1 Hongo Bunkyo, Tokyo 113-0033,

Japan.

e-mail:katoj@j.u-tokyo.ac.jp

Dr. Kenji Kansaku, Cognitive Functions Section, Department of Rehabilitation for Sensory Functions, Research Institute of National Rehabilitation Center for Persons with Disabilities, 4-1 Namiki, Tokorozawa, Saitama 359-8555, Japan.

e-mail: kansaku-kenji@rehab.go.jp

${ }^{\dagger}$ Junko Kato and Hiroko Ide contributed equally to this work.
Understanding changes in attitudes towards others is critical to understanding human behaviour. Neuropolitical studies have found that the activation of emotion-related areas in the brain is linked to resilient political preferences, and neuroeconomic research has analysed the neural correlates of social preferences that favour or oppose consideration of intrinsic rewards. This study aims to identify the neural correlates in the prefrontal cortices of changes in political attitudes toward others that are linked to social cognition. Functional magnetic resonance imaging (fMRI) experiments have presented videos from previous electoral campaigns and television commercials for major cola brands and then used the subjects' self-rated affinity toward political candidates as behavioural indicators. After viewing negative campaign videos, subjects showing stronger $\mathrm{fMRl}$ activation in the dorsolateral prefrontal cortex lowered their ratings of the candidate they originally supported more than did those with smaller $\mathrm{fMRI}$ signal changes in the same region. Subjects showing stronger activation in the medial prefrontal cortex tended to increase their ratings more than did those with less activation. The same regions were not activated by viewing negative advertisements for cola. Correlations between the selfrated values and the neural signal changes underscore the metric representation of observed decisions (i.e., whether to support or not) in the brain. This indicates that neurometric analysis may contribute to the exploration of the neural correlates of daily social behaviour.

Keywords: attitude changes, fMRI, neuropolitics, neuroeconomics, human

\section{INTRODUCTION}

Exploring human nature is one of the primary motivations for investigations in neuroscience. We explored the neural mechanism involved in preference changes toward others in a situation that is relevant to social life, the exposure to positive and negative advertisements.

The (dis)favour in which others are held, and changes thereto, might affect decisions. Attitudes and attitude changes have constituted major concerns of political psychology (Mutz et al., 1996). In this regard, stable preferences towards others, such as those based on partisanship and membership in social groups, as well as preferences that are more susceptible to change constitute important subjects for study. Psychological tests to identify affinity with sociopolitical groups (such as political organizations and ethnic groups) provide reliable indicators of stable preferences. Neuropolitical experiments use stimuli that reinforce or oppose the stable political preferences of subjects. Initial studies have discovered circuitry in regions of the brain that are related to emotion (Kaplan et al., 2007; Knutson et al., 2006; Phelps et al., 2000; Westen et al., 2006). Traditionally, economic theory has assumed that people are concerned exclusively with their own interests, but the recognition of (positive and negative) concern about the welfare of others has already become the conventional wisdom in experimental and behavioural economics (Camerer, 2008; Carpenter, 2008). In neuroeconomics, social preferences are identified as divergence from purely self-interested choices in which subjects consider only their own primary rewards. Neuroeconomics experiments have identified the neural circuitry of social preferences as part of the reward-related regions of the brain (Fehr and Camerer, 2007; Lee, 2008; Loewenstein et al., 2008).

Studies on political decisions have paralleled those on economic ones (Mueller, 2003) in social science, and political scientists have increasingly considered this parallel as relevant (Katznelson and Weingast, 2005). Both political and economic decisions can be regarded as involving self- as well as other-oriented concerns. However, unlike economic self-interested behaviour, political self-interested behaviour is not necessarily defined by utility functions, and concern about others is not explicitly related to considerations of the welfare of others. Whereas economic theory defines utility functions that relate subjective goals (represented as choices) to objective values (such as the amount, probability, and time delay of reward), a variety of social behaviours, including political behaviours, might not necessarily be related to objective measures. Thus, our experiments used self-ratings of affinity towards others that political scientists have used to quantify political preferences. A recent experiment in neuroeconomics has shown that neural activity related to the acquisition of rewards tracks the subjective values of delayed monetary rewards (Kable and Glimcher, 2007). While subjective values of political preferences are not externally quantified, their changes that are focused in our experiments are metrically represented in brain activities. 
Our experiments focused on the prefrontal cortices that are linked to cognitive control (Canessa et al., 2005; Lieberman, 2007; Miller and Cohen, 2001) because we hypothesized that this region contributes to changes in preferences caused by relevant stimuli that affect social cognition. Focusing on real implications, we explored the association between preference changes and neural activities by using videos from the 1992 US presidential campaign and the commercials of major cola brands for comparison. Although social scientists agree that negative campaigns affect voters' behaviours, they are divided about their influence on individual psychology and, ultimately, attitude (Lau et al., 2007). To explore the neural mechanisms, our experiment combined the neurometric analysis with two distinct behavioural observations: the binary judgment on which rival candidate (or commodity) is favoured after viewing the videos and the self-scaled affinity towards candidates in post-task questionnaires.

On the one hand, after viewing negative campaign videos, subjects showing stronger functional magnetic resonance imaging (fMRI) activation in the dorsolateral prefrontal cortex lowered their ratings for the candidate they originally supported more than did those with weaker fMRI activation in the same cortical area. On the other hand, subjects showing stronger activation in the medial prefrontal cortex tended to increase their ratings for the candidates attacked in the negative campaign videos more than did those with weaker activation. The same regions were not activated while viewing negative advertisements for cola, which were used for purposes of comparison. These results imply that neural activity after exposure to negative information about previously supported political candidates was linked to cognitive control of socially relevant stimuli. The activation of distinct prefrontal areas indicates that different kinds of cognitive controls were associated with opposite responses to negative information about the previously supported candidates, that is, they were associated with increasing and decreasing political support. fMRI signal changes in the dorsolateral prefrontal cortex showed negative correlations with changes in ratings for the candidates after viewing the negative campaign videos against them and the changes in the medial prefrontal cortex showed positive correlations. The neuronal representation of self-rated affinity towards others might lead to methodological advances in the analysis of those social behaviours that cannot be quantitatively defined by an external measurement explicitly expressed as a utility function.

\section{MATERIALS AND METHODS SUBJECTS AND BEHAVIOURAL TASK}

Forty, healthy volunteers ( 8 women and 32 men, aged 18-27 years), who were native English speakers or able to understand TV news in English, were pre-assessed to exclude those ineligible for magnetic resonance (MR) scanning. All of the subjects were neurologically normal and strongly right-handed according to the Edinburgh Inventory (Oldfield, 1971). A pre-scanning questionnaire also asked their gender, age, and ideology. We recruited those who were under 30 years old at the time of the experiment (summer 2007) to avoid those who had seen presidential campaign advertisements in 1992. No one had seen any of the campaign ads we presented. All participants gave informed consent for the study, which had been approved by the Institutional Review Board.

We used videos from the 1992 US presidential campaign and ads for two cola brands for comparison. Participants spent three sessions viewing presidential campaign advertisements (Bush vs. Clinton) and three viewing cola advertisements (Coke ${ }^{\circledR}$ vs. Pepsi ${ }^{\circledR}$ ) inside an MRI machine (Figure 1). The order of the six sessions (both political and commercial ads) was counterbalanced among the participants; about half the participants experienced the six sessions in the reverse order. After each session, they were asked which candidate (or cola brand) they favoured. For both the campaign and cola advertisements, positive advertisements about each candidate (or brand) were shown in the first session, followed by a second session of negative advertisements that attacked the candidate/brand of choice. The third session again showed positive advertisements for both sides, but
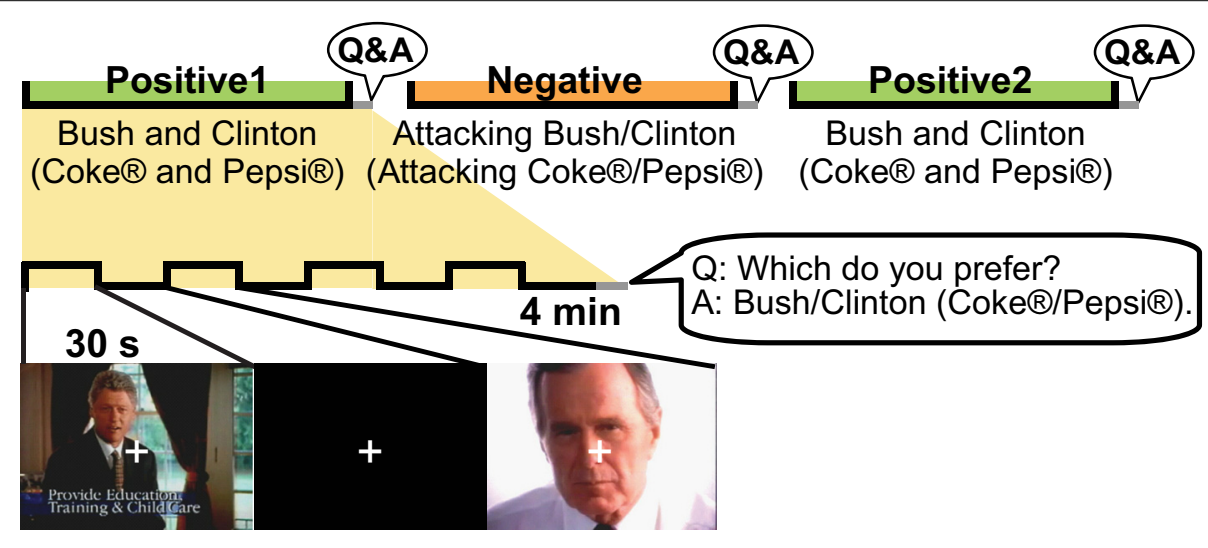

FIGURE 1 | Tasks inside the MR machine. Three sessions of campaign advertisements and three sessions of cola advertisements were shown. After each session, the participants were asked which of the two candidates/brands they favoured. For both the campaign and cola advertisements, the first session consisted of positive advertisements for both candidates/brands. The candidate/ brand favoured after the first session was attacked during the second session. The third session again consisted of positive advertisements for both candidates/brands, but the content differed from that of the first session. One advertisement session consisted of four segments of 30-s advertisements with each advertisement followed by a 30 -s rest period. 
the content differed from the first session. One advertisement session consisted of four segments of 30-s advertisements; each advertisement was followed by a 30-s rest period. For the political campaign advertisements, participants were asked in a post-task questionnaire to rate how (un)favourable they felt towards each candidate after each session. Using an analogy with thermometry for expressing cold- and warm-heartedness, they were instructed to give a rating of 50 [in a range from 0 (least favourable) to 100 (most favourable)] when they were neutral about a candidate. This rating was built on a measure of the so-called "feeling thermometer," used by the Center for Political Studies, University of Michigan, to analyse presidential elections since 1968 (Weisberg and Miller, 1979), and studies of elections and social groups (Cairns et al., 2006).

During the experiment, each participant lay supine on the stretcher of an MR scanner (Exelart; Toshiba, Tokyo, Japan) with his/her head fixed with straps and pads inside the head coil to restrict head motion. The six sessions of advertisement videos were projected onto a screen located at the rear of the scanner and viewed through a mirror attached to the top of the head coil. The sound accompanying the advertisements was delivered through headphones. The participants wore earplugs under the headphones to minimise the MR scanner noise. Before starting the experiment, each participant confirmed that he/she could see the screen and hear the sound clearly. They were instructed to fixate on or view the images around a white cross (a fixation point) at the centre of the screen to minimise artefacts related to eye movements. The stimulus was presented and synchronised with the MR scanner using Presentation ${ }^{\circledR}$ (Neurobehavioral Systems, San Francisco, CA, USA).

\section{IMAGING}

During the video sessions, gradient echo $\mathrm{T} 2^{\star}$ weighted echo-planar images with BOLD contrast were acquired at $1.5 \mathrm{~T}(\mathrm{TR} / \mathrm{TE}=3000$ / $40 \mathrm{~ms}, \mathrm{FA}=85^{\circ}$, slice thickness/gap $=6 / 2 \mathrm{~mm}, \mathrm{FOV}=25 \times 25 \mathrm{~cm}^{2}$, matrix size $=64 \times 64,18$ slices $)$. Each of the six sessions consisted of 85 scans, the first five of which were discarded to allow for T1 equilibration effects. T1-weighted structural images were also acquired after the video sessions.

\section{IMAGING ANALYSIS}

The imaging data were pre-processed and analysed using SPM5 (Wellcome Department of Imaging Neuroscience, Institute of Neurology, University College London, UK). The realignment processing assured that the participant's head movement was less than $2 \mathrm{~mm}$. The realigned images were then normalised to a Montreal Neurological Institute (MNI) EPI template and smoothed with an 8-mm full-width at half maximum Gaussian kernel. A highpass filter with a cut-off period of $128 \mathrm{~s}$ was applied to remove low-frequency noise, and an autoregressive (order one) model was used to correct for short-range serial correlations.

A fixed-effects analysis was conducted for each participant to obtain a contrast image for each advertisement session. The contrast images of the 40 participants were then used for random effects analysis. To evaluate fMRI activation within the prefrontal cortices associated with a change in choice of the favoured candidate, we first conducted a $t$-test between the Changed and Unchanged
Groups for each of the two negative and two subsequent positive advertisement sessions. In the comparison, we inclusively masked areas where the mean per cent signal change for the group that had lower activations was more than zero to avoid picking up brain areas that show deactivations predominantly in our analysis. Random effect SPM $\{\mathrm{t}\}$ maps were thresholded at an uncorrected $p<0.05$, with a cluster- size threshold of 15 voxels. The MNI co-ordinates were converted to Talairach co-ordinates (Talairach and Tournoux, 1988) using the nonlinear transformations suggested by Brett ${ }^{1}$; the corresponding Brodmann areas (BA) were first assumed roughly using Talairach Daemon (Lancaster et al., 2000) and then determined using the atlas of Talairach and Tournoux (Talairach and Tournoux, 1988). We then extracted the time courses of each cluster in the prefrontal area using $\mathrm{MarsBaR}^{2}$ for the six advertisement sessions. The average per cent signal change for each participant for each session was calculated relative to the average signal obtained during the rest period.

Using the per cent signal change data obtained from each individual, we performed a between-subjects correlation analysis for the behavioural indicators: the aforementioned self-rated preferences for the candidates (feeling thermometer). All clusters that survived the $t$-test with inclusive masking were examined. A behavioural indicator representing the degree of preference change towards a favoured candidate during a campaign advertisement session was calculated by subtracting "the pre-session rating of the favoured candidate" from "the post-session rating of the candidate." An additional indicator that represents a relative preference for a favoured candidate was calculated by subtracting "the pre-session rating of the unfavoured candidate" from "the pre-session rating of the favoured candidate." For the regions of interest, a two-sample $t$-test of the signal changes of the Changed and Unchanged Groups (two-tailed; $p<0.05$ ) was also performed for each session.

\section{RESULTS}

\section{BEHAVIOURAL ANALYSIS}

The choice of favoured candidate and cola brand after each session for the political advertisements and cola advertisements are shown in Figures 2 and 3. Of the 34 people who chose Clinton after the first session, 14 changed their choices after seeing negative advertisements attacking Clinton, whereas four of out of six people who had chosen Bush chose Clinton after the negative advertisements. In other words, 18 of the 40 participants who saw negative advertisements attacking the candidate of their choice changed their choices after viewing the negative advertisements (Figure 2). Seven of the 20 people who had chosen Pepsi ${ }^{\circledR}$ changed their minds, whereas 4 out of the 20 people who had chosen Coke ${ }^{\circledR}$ changed their choices to Pepsi after viewing the negative advertisements. That is, 11 people changed their choices after viewing negative cola advertisements (Figure 3).

We performed Wilcoxon's rank-sum tests for sex, age, and ideology to identify statistically significant relationships between changes in choices and participants' attributes. Only age was significantly related to changes in choice, and only with regard to the second positive political session. This indicates that the younger

\footnotetext{
${ }^{1}$ http://imaging.mrc-cbu.cam.ac.uk/imaging/MniTalairach
}

${ }^{2} \mathrm{http}: / /$ marsbar.sourceforge.net 


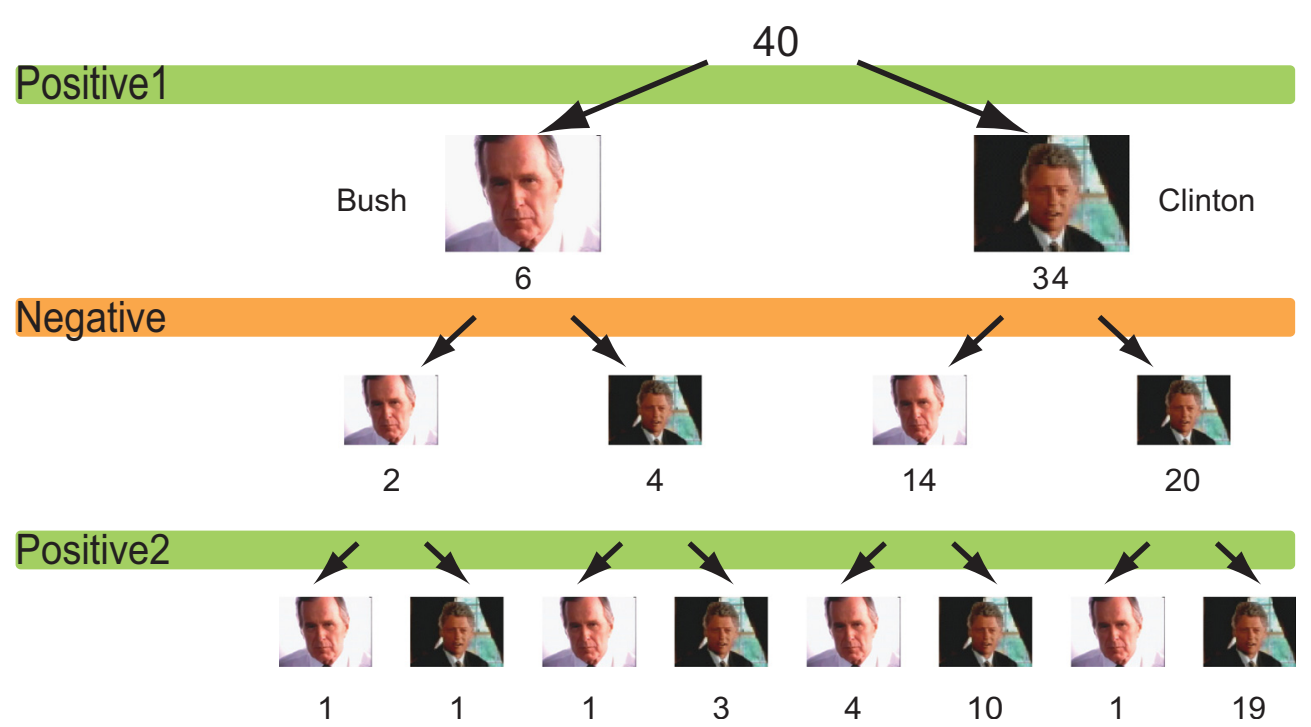

FIGURE 2 | Choice of candidates. The number of participants who chose either Bush or Clinton after each campaign advertisement session.

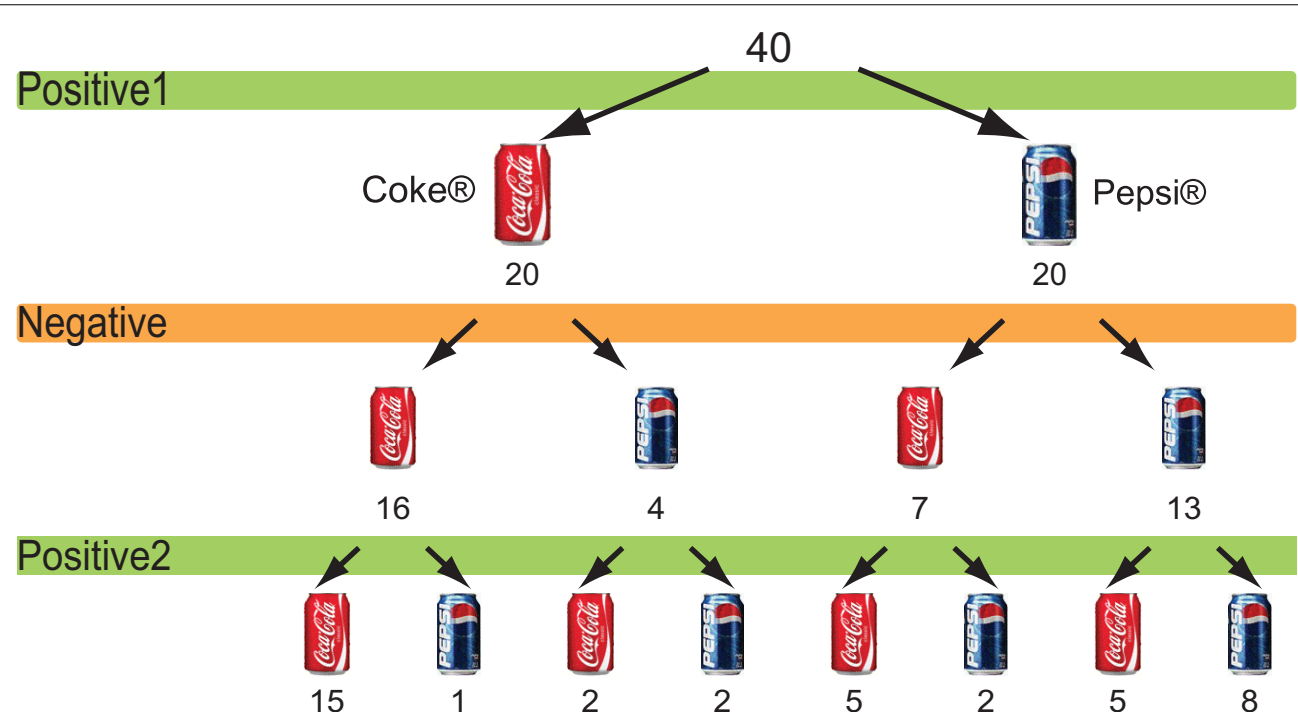

FIGURE 3 | Choice of cola brands. The number of participants who chose either cola brand after each cola advertisement session.

participants changed more often after viewing the second, positive campaign session.

We also conducted correlation analyses to examine if our main behavioural indicator, preference change for the favoured candidate during the negative campaign advertisement session (the post-session rating of the attacked candidate vs. the pre-session rating of the attacked candidate), could be explained by other behavioural indicators. We found that the indicator was negatively correlated $(-0.4363 ; p=0.0049)$ with the pre-session rating of preference towards the favoured candidate after the first positive advertisement session and negatively correlated $(-0.3757$; $p=0.0169$ ) with the pre-session rating of preference for the nonfavoured candidate.

\section{NEURAL ANALYSIS}

To identify brain regions in which subjective values, especially preference changes related to changes in choices, are represented metrically, we first compared those whose candidate choice did not change after viewing the advertisements (Unchanged Group) with those whose choice did change (Changed Group). The Talairach co-ordinates of the clusters that remained in this analysis are listed in Table $\mathbf{1 .}$

As is the case in much of the literature on social cognition, our investigation focused on the prefrontal cortices. During the negative campaign advertisements, the Unchanged Group had more activations than the Changed Group in the medial prefrontal regions. The degree of preference change towards the favoured (attacked) candidate during the negative advertisement session 
Table 1 | Brain areas detected in the group (random effect) analyses.

\begin{tabular}{|c|c|c|c|c|c|}
\hline Brain region (Brodmann area) & $x$ & $y$ & $z$ & t-Statistic & $p$-Value \\
\hline \multicolumn{6}{|l|}{ Unchanged $>$ Changed } \\
\hline Left middle temporal gyrus (39) & -42 & -52 & 12 & 2.81 & 0.004 \\
\hline Left middle temporal gyrus (21) & -65 & -35 & -8 & 2.70 & 0.005 \\
\hline Left lingual gyrus (18) & -8 & -64 & 3 & 2.54 & 0.008 \\
\hline Right cuneus (19) & 22 & -76 & 33 & 2.12 & 0.020 \\
\hline Right superior temporal gyrus (39) & 46 & -52 & 14 & 2.04 & 0.024 \\
\hline Left superior frontal gyrus (8) & -16 & 39 & 44 & 2.03 & 0.024 \\
\hline Left cerebellum & -6 & -41 & -5 & 2.02 & 0.025 \\
\hline Right superior temporal gyrus (41) & 42 & -36 & 9 & 2.00 & 0.026 \\
\hline Left cerebellum & -34 & -82 & -16 & 3.41 & 0.001 \\
\hline Right occipital gyrus (19) & 40 & -78 & 4 & 4.10 & 0.000 \\
\hline Left inferior/middle frontal gyrus (9/6) & -42 & 16 & 40 & 3.99 & 0.000 \\
\hline Right cerebellum & 14 & -26 & -14 & 3.55 & 0.001 \\
\hline Left superior temporal gyrus (38) & -50 & 14 & -21 & 3.35 & 0.001 \\
\hline Right inferior/middle frontal gyrus (46/9) & 53 & 30 & 11 & 3.30 & 0.001 \\
\hline Left cuneus (19) & -30 & -88 & 28 & 3.10 & 0.002 \\
\hline Left superior parietal lobule (7) & -24 & -71 & 55 & 2.63 & 0.006 \\
\hline Left inferior frontal gyrus (46) & -46 & 30 & 13 & 2.51 & 0.008 \\
\hline Left precentral gyrus (4) & -63 & -10 & 28 & 2.36 & 0.012 \\
\hline \multicolumn{6}{|l|}{ POLITICAL POSITIVE2 ADVERTISEMENTS } \\
\hline \multicolumn{6}{|l|}{ Unchanged $>$ Changed } \\
\hline Left precuneus (7) & -16 & -77 & 46 & 3.90 & 0.000 \\
\hline Right posterior cingulate (29) & 10 & -42 & 8 & 3.37 & 0.001 \\
\hline Right lingual gyrus/cuneus (18) & 4 & -84 & -11 & 2.89 & 0.003 \\
\hline Left fusiform gyrus (19) & -22 & -59 & -9 & 2.47 & 0.009 \\
\hline Anterior cingulate (32) & 0 & 25 & -11 & 2.46 & 0.009 \\
\hline Right fusiform gyrus (19) & 24 & -55 & -7 & 2.45 & 0.009 \\
\hline Left middle temporal gyrus (21) & -65 & -37 & -8 & 2.43 & 0.010 \\
\hline Right fusiform gyrus (37) & 46 & -59 & -14 & 2.34 & 0.012 \\
\hline Right superior temporal gyrus (38) & 44 & 10 & -27 & 2.34 & 0.012 \\
\hline Left fusiform gyrus (19) & -44 & -74 & -11 & 2.30 & 0.013 \\
\hline Left cerebellum & -34 & -34 & -24 & 2.27 & 0.014 \\
\hline Right middle temporal gyrus (21) & 46 & -14 & -9 & 2.13 & 0.020 \\
\hline Right superior/middle temporal gyrus (21/22) & 48 & -29 & 1 & 2.11 & 0.021 \\
\hline Left hippocampus & -30 & -16 & -11 & 2.00 & 0.026 \\
\hline Right lingual gyrus (18) & 26 & -74 & -8 & 1.96 & 0.028 \\
\hline Right supramarginal gyrus (40) & 57 & -50 & 19 & 1.96 & 0.029 \\
\hline
\end{tabular}


Table 1 | Continued

\begin{tabular}{|c|c|c|c|c|c|}
\hline Brain region (Brodmann area) & $x$ & $y$ & $z$ & $t$-Statistic & $p$-Value \\
\hline Left middle occipital gyrus (19) & -40 & -71 & 20 & 1.92 & 0.031 \\
\hline Left precuneus (19) & -28 & -70 & 35 & 1.87 & 0.034 \\
\hline \multicolumn{6}{|l|}{ Changed $>$ Unchanged } \\
\hline Left middle/superior temporal gyrus (21/38) & -57 & 3 & -10 & 4.02 & 0.000 \\
\hline Right medial frontal gyrus (10) & 16 & 61 & 6 & 3.24 & 0.001 \\
\hline Right inferior parietal lobule (7) & 38 & -56 & 54 & 2.85 & 0.004 \\
\hline Left middle temporal gyrus (37) & -48 & -56 & -1 & 2.75 & 0.005 \\
\hline Right superior temporal gyrus (42) & 51 & -17 & 5 & 2.64 & 0.006 \\
\hline Right cerebellum & 34 & -60 & -27 & 2.50 & 0.008 \\
\hline Right inferior frontal gyrus (46) & 51 & 41 & 11 & 2.44 & 0.010 \\
\hline Right superior temporal gyrus (22/42) & 67 & -31 & 11 & 2.16 & 0.018 \\
\hline Left cerebellum & -26 & -44 & -31 & 2.07 & 0.022 \\
\hline Right inferior frontal gyrus (9) & 42 & 9 & 29 & 2.07 & 0.023 \\
\hline Right precuneus (7) & 22 & -56 & 36 & 2.05 & 0.023 \\
\hline Right inferior frontal gyrus (11) & 24 & 27 & -13 & 2.04 & 0.024 \\
\hline Left middle frontal gyrus (11) & -16 & 27 & -11 & 2.01 & 0.026 \\
\hline Left precuneus (7) & -20 & -57 & 34 & 2.00 & 0.026 \\
\hline Right cingulate gyrus (23) & 6 & -40 & 24 & 1.90 & 0.032 \\
\hline \multicolumn{6}{|l|}{ COLA NEGATIVE ADVERTISEMENTS } \\
\hline \multicolumn{6}{|l|}{ Unchanged > Changed } \\
\hline Right middle temporal gyrus (21) & 55 & -16 & -9 & 2.91 & 0.003 \\
\hline Left inferior frontal gyrus (46) & -53 & 32 & 9 & 2.72 & 0.005 \\
\hline Left superior/medial frontal gyrus (9) & -4 & 58 & 30 & 2.68 & 0.005 \\
\hline Left superior occipital gyrus (19) & -46 & -81 & 19 & 2.67 & 0.006 \\
\hline Left parahippocampal gyrus (35) & -18 & -33 & -7 & 2.36 & 0.012 \\
\hline Right lingual gyrus (18) & 6 & -86 & -4 & 2.27 & 0.014 \\
\hline Left precentral gyrus (4/6) & -40 & -6 & 44 & 2.16 & 0.018 \\
\hline Right parahippocampal gyrus & 22 & -16 & -11 & 2.14 & 0.019 \\
\hline Left superior frontal gyrus (8) & -8 & 38 & 52 & 2.12 & 0.020 \\
\hline Right superior parietal lobule (7) & 14 & -57 & 67 & 2.09 & 0.021 \\
\hline Right middle frontal gyrus (6) & 28 & 11 & 62 & 2.07 & 0.022 \\
\hline Left precentral gyrus (6) & -57 & 7 & 33 & 1.90 & 0.032 \\
\hline \multicolumn{6}{|l|}{ Changed $>$ Unchanged } \\
\hline Right cuneus (18) & 14 & -99 & 3 & 3.21 & 0.001 \\
\hline Right thalamus & 16 & -19 & 8 & 2.91 & 0.003 \\
\hline Right precentral/inferior frontal gyrus (6/9) & 30 & 7 & 25 & 2.68 & 0.005 \\
\hline Right cerebellum & 34 & -56 & -24 & 2.67 & 0.005 \\
\hline Left cuneus (18) & -12 & -101 & 9 & 2.35 & 0.012 \\
\hline Left thalamus & -22 & -21 & 10 & 2.30 & 0.014 \\
\hline
\end{tabular}


Table 1 | Continued

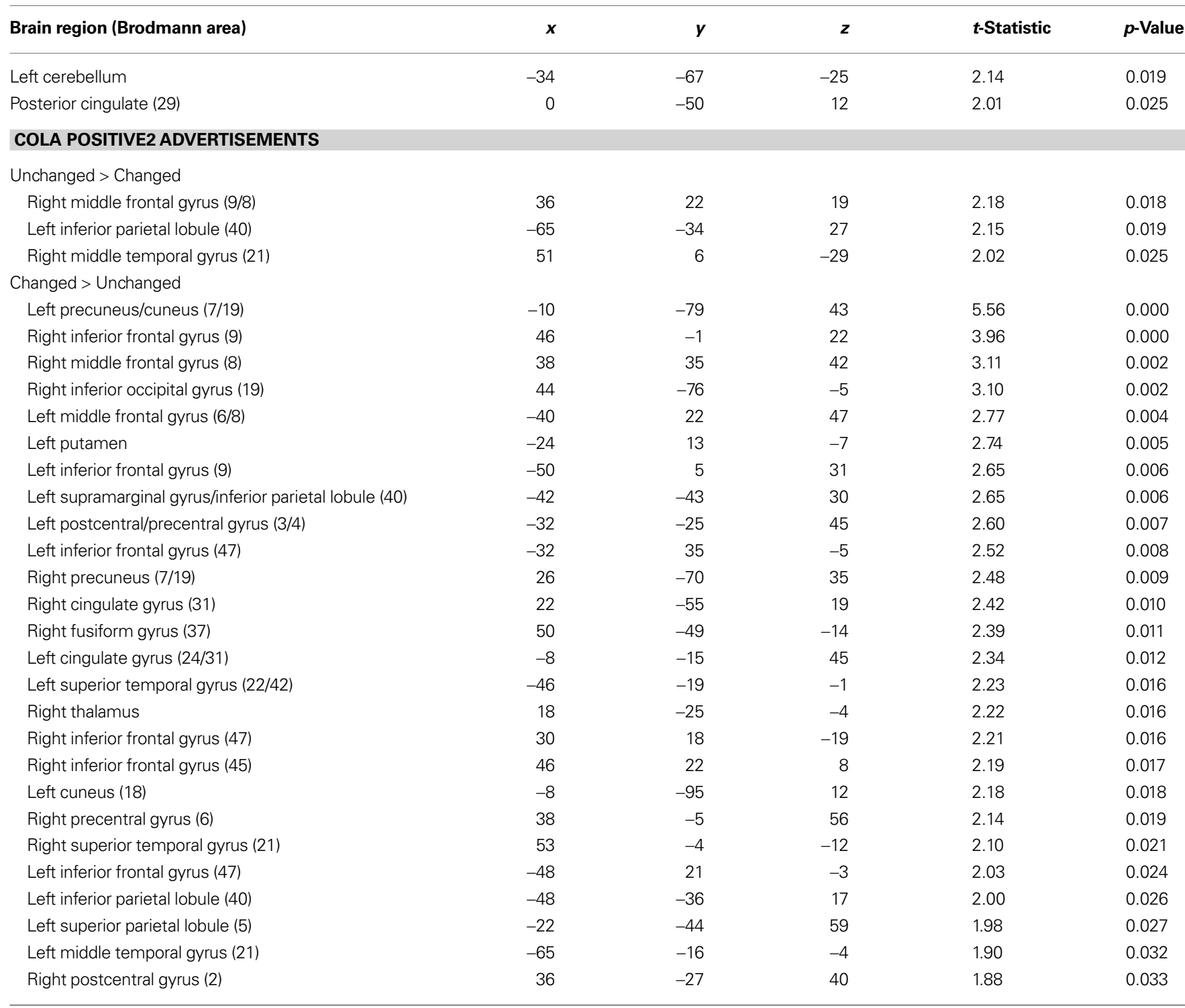

$t$-test, uncorrected $p<0.05$. Inclusively masked with the areas where the mean per cent signal change for the group that had lower activations was greater than zero. Cluster size of more than 15 voxels.

had a significant positive correlation with the per cent signal change in one of these regions (Talairach co-ordinate: $-16,39$, 44; BA8; Figure 4A).

By contrast, the Changed Group had more activations than the Unchanged Group in the right and left dorsolateral prefrontal regions, and the same degree of preference change towards the favoured (attacked) candidate during the negative advertisement session had significant negative correlations with the per cent signal change in these two regions $[(-42,16,40 ; \mathrm{BA} 9 / 6)$ and $(53,30,11$; BA46/9), respectively; Figures 5A and 6A]. Among the prefrontal regions that showed significantly different activations between the Unchanged Group and Changed Group (uncorrected $p<0.05$ ), only these three regions exhibited significant correlations with our preference-related indicators.
Furthermore, an additional preference rating, the relative preference for the favoured candidate measured before the negative advertisements was significantly positively correlated with the signal change in the left medial prefrontal region (Figure 7), but not with that in the two dorsolateral prefrontal regions.

For these three regions, we also compared the signal change in the Unchanged and Changed Groups for all six advertisement sessions to see if significantly different activations also occurred in other sessions. We found that the left medial prefrontal region was activated significantly more in the Unchanged Group during the negative political advertisement session only (Figure 4B) This indicates that the activation of this part of the brain was specific to the political task in our experiment and to the negative advertisements among political sessions. Conversely, the 


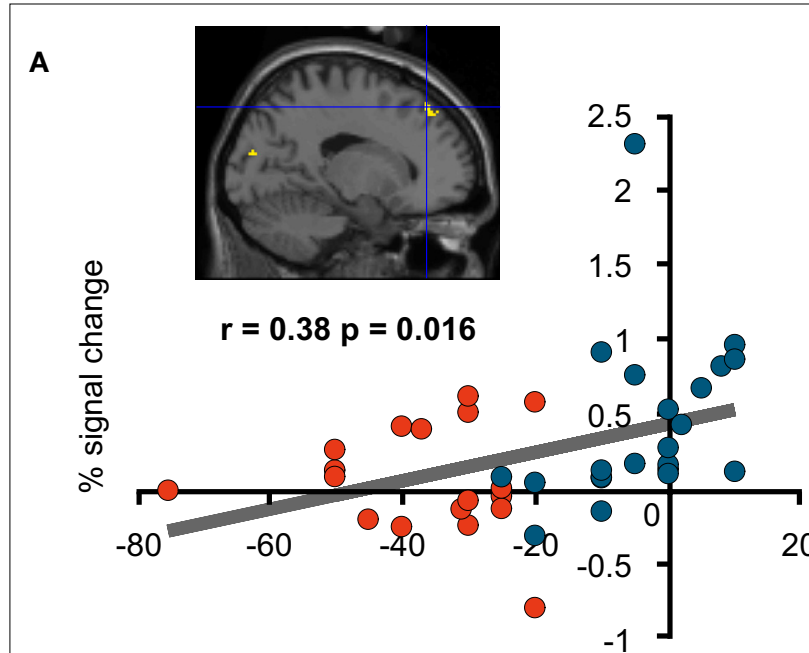

Preference Change for Attacked Candidate

B

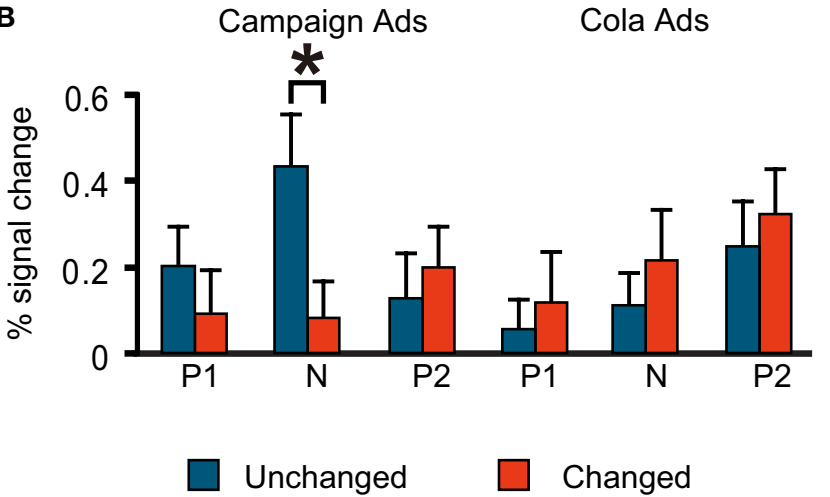

FIGURE 4 | fMRI signal change at the medial prefrontal cortex $(-16,39$, 44; BA8). (A) Correlation between the signal change during the negative advertisements and preference change towards a favoured candidate during the negative advertisements (=post-negative-advertisement preference for the attacked candidate - pre-negative-advertisement preference for the attacked candidate). Blue, Unchanged; red, Changed. Note that each plot represents an individual subject. (B) Mean comparison between the Unchanged and Changed Groups for each advertisement session. P1, Positive1; N, Negative; P2, Positive2. The asterisk indicates a significant difference at $p<0.05$ ( $t$-test). The error bars are the S.E.M.)

dorsolateral prefrontal regions were activated significantly more in the Changed Group in all political sessions, but not in the cola sessions (Figures 5B and 6B); therefore, these areas were politicsspecific, but not negative-specific in our tasks. In addition, prefrontal regions that were activated more in the Unchanged Group during the cola negative advertisements were found, but at coordinates that were different from those found for the political negative advertisements (for the co-ordinates, see Table 1). These findings also indicate that the prefrontal regions had different associations with preference change in response to the negative campaign advertisements and the negative cola advertisements.

During the second sessions of positive advertisements for both the campaign and cola advertisements, the Changed Group showed

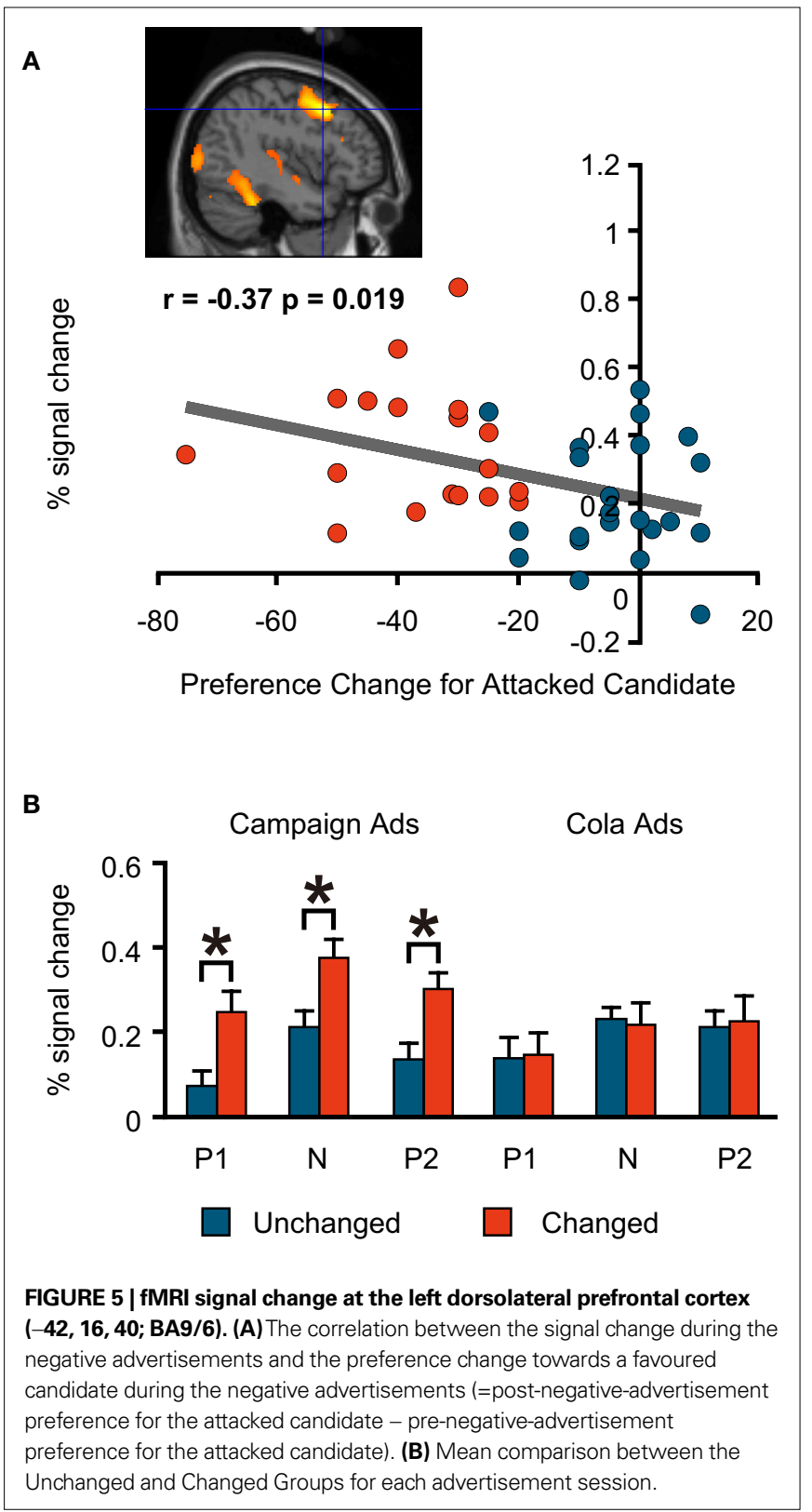

more activations in the dorsolateral prefrontal cortices $(51,41,11$; BA46), (42, 9, 29; BA9) and (-32, 7, 31; BA9/6) for campaign and $(46,-1,22$; BA9) and $(-50,5,31$; BA9) for cola. Activation in the dorsolateral prefrontal cortex $(36,22,19 ; \mathrm{BA} 8 / 9)$ was also found in the Unchanged Group, but only during the cola session. As in the case of the negative campaign advertisements, the per cent signal change in the right dorsolateral prefrontal cortex $(51,41,11$; BA46) during the second, positive campaign advertisements had a negative correlation with the preference change for the candidate that had been favoured before the second, positive advertisements (Figure 8). In addition to the dorsolateral prefrontal cortices, the reward-related ventromedial prefrontal area $(16,61,6$; BA10) was found to be activated more in the Changed Group during the second, positive campaign advertisements. The area did not show correlated activities with the self-scaled values, but survived a correction for 


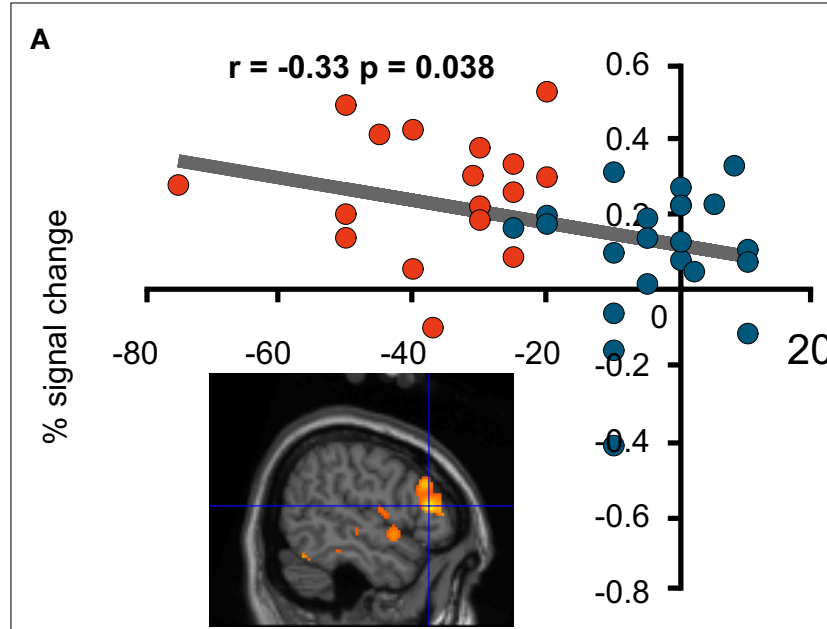

Preference Change for Attacked Candidate

B

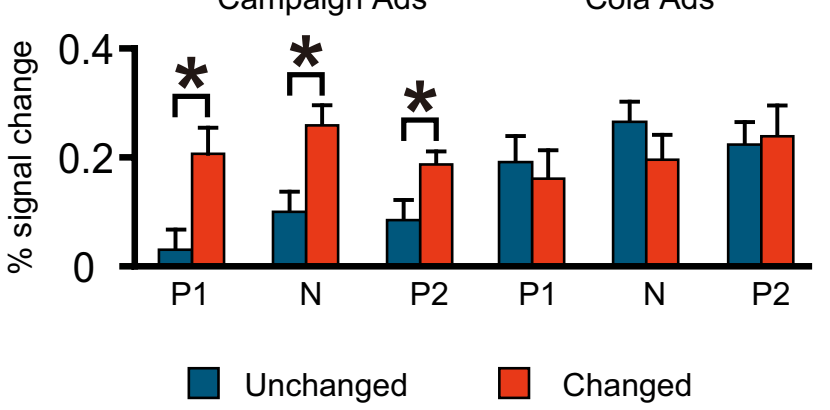

FIGURE 6 | fMRI signal change at the right dorsolateral prefrontal cortex $\mathbf{( 5 3 , 3 0 , 1 1 ; B A 4 6 / 9 ) . ~ ( A ) ~ C o r r e l a t i o n ~ b e t w e e n ~ t h e ~ s i g n a l ~ c h a n g e ~ d u r i n g ~ t h e ~}$ negative advertisements and the preference change towards a favoured candidate during the negative advertisements (=post-negative-advertisement preference for the attacked candidate - pre-negative-advertisement preference for the attacked candidate). (B) Mean comparison between the Unchanged and Changed Groups for each advertisement session.

multiple comparisons using a false discovery rate when a one-sample $t$-test $(p<0.05)$ was conducted for the Changed Group.

\section{DISCUSSION}

We demonstrated that neural activation in several different regions in the prefrontal cortex traced a change in subjective values of affinity towards political candidates. The findings involved implications for understanding preference changes towards others after receiving negative information on them. Neural signal changes in the lateral prefrontal cortex had significant negative correlations with an increase in preference for the supported candidate after viewing the negative campaign videos. Changes in the medial prefrontal cortex had positive correlations. The medial and lateral prefrontal cortices were associated with opposite responses, i.e., continued support or changing sides, respectively, in our experiment. Thus, we confirmed the neural correlates of two critical elements in real politics: a binary choice between two competing alternatives (i.e., maintaining or switching support) and a transformation in preference that predicates the choice.

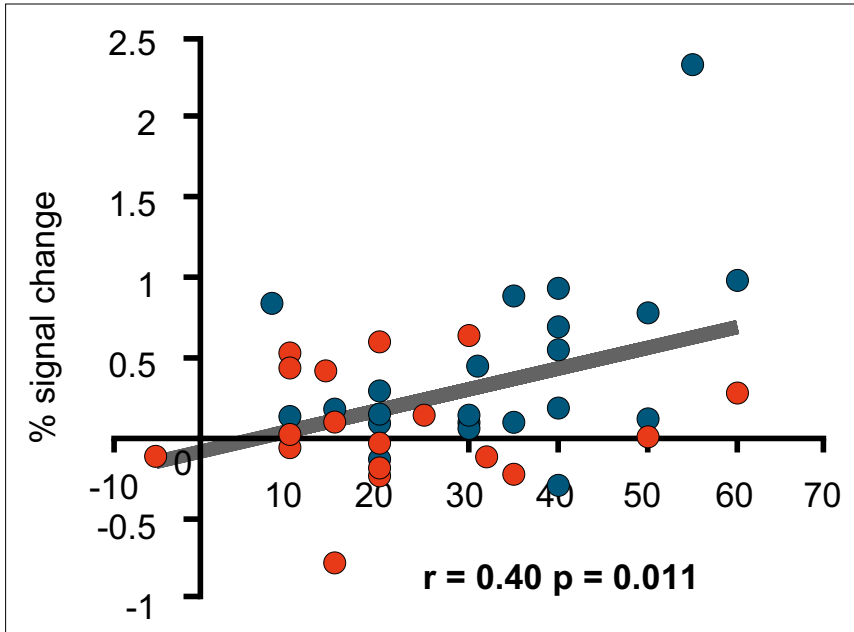

Relative Preference for Attacked Candidate

FIGURE 7 | fMRI signal change at the medial prefrontal cortex. The figure shows the correlation between the signal change at $(-16,39,44$; BA8) during the negative advertisements and the relative preference for a favoured candidate before the negative advertisements (=the pre-session rating of the attacked candidate - the pre-session rating of an attacking candidate).

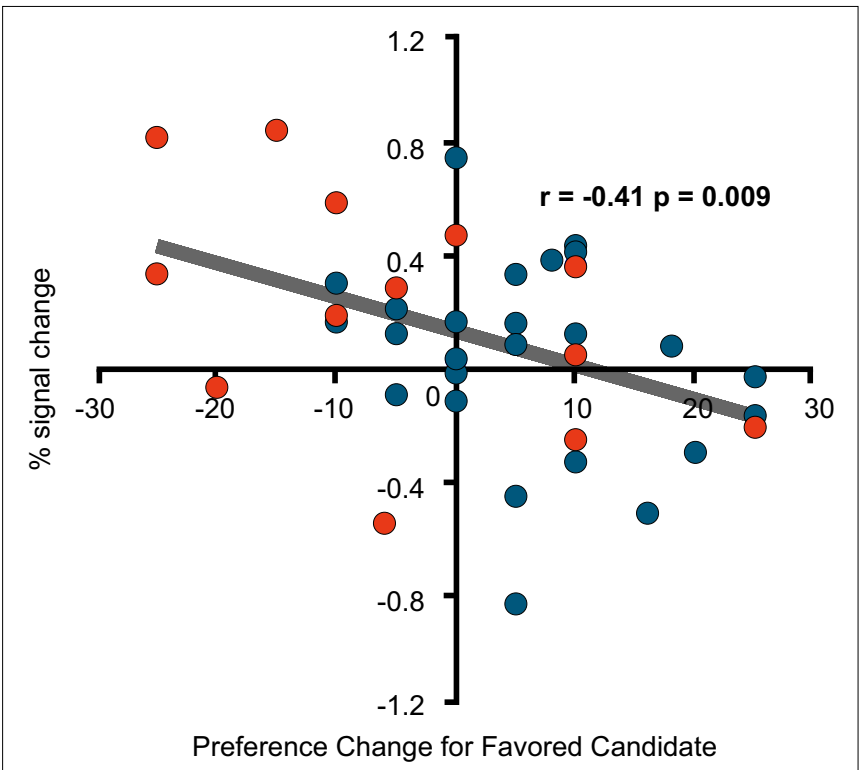

FIGURE 8 | fMRI signal change at the right dorsolateral prefrontal cortex. Correlation between the signal change at $(51,41,11$; BA46) during the second, positive advertisements and the preference change for the favoured candidate during the second, positive advertisements [=the post-session rating of the (originally) favoured candidate - the pre-session rating of the favoured candidate].

\section{ACTIVATION IN THE MEDIAL PREFRONTAL CORTEX}

The prefrontal cortex, where we found the activated regions, is thought to be associated with social cognitive control (Canessa et al., 2005; Lieberman, 2007; Miller and Cohen, 2001). The medial prefrontal cortex, especially the posterior rostral medial prefrontal cortex, is implicated in conflict monitoring (Amodio and Frith, 2006). Deductive reasoning is thought to be important 
when selecting one among conflicting alternatives (Goel, 2007). In published experiments, activation of BA8 was reported when monitoring a conflict among competing alternatives in the face of uncertainty. In predicting a winner between two UFOs with different colours, shapes, and figures, BA8 was commonly recruited in the face of uncertainty that derived from varying winning probabilities, whereas different strategies to cope with uncertainty might recruit different neural circuits (Volz et al., 2004, 2005). The medial BA8 was also recruited in a task that required the individual to judge the validity of an argument and select one from among alternatives that are different in deductive complexity. The activated region $(-16,39$, 44: BA8) among the Unchanged Group in our experiment is similar to the one used when subjects were required to judge the validity of logical statements matched in linguistic complexity by using deduction (Monti et al., 2007). The nature of the behaviour framed in previous experiments parallels the behaviour of our experiment in the sense that the subjects were required to make a binary choice based on deduction when facing uncertainty. The neural correlate implies that the Unchanged Group chose to continue to support a favoured candidate based on a deductive examination of conflicting information presented in the negative advertisements. The activation of BA8 was observed in the Unchanged Group during politically negative advertisements, but not during positive ones or in the cola tasks.

\section{ACTIVATION IN THE DORSOLATERAL PREFRONTAL CORTEX}

Induction was also adopted as a strategy for making a decision if an explicit pattern in uncertainty did not emerge, that is, the stimulus (i.e., the message in the campaign advertisements) did not necessarily control the level of uncertainty by varying probabilities (Volz et al., 2004, 2005) or logical (in)consistency (Monti et al., 2007). The region activated among the Changed Group was the bilateral dorsolateral prefrontal cortices (BA9/6, BA46/9), which are associated with induction rather than deduction (Goel and Dolan, 2004) and with working memory (Miller and Cohen, 2001). More specifically, the activation in the dorsolateral prefrontal cortex is thought to increase when attention is focussed on goal-relevant stimuli while minimising distraction from cross-modal stimuli (Weissman et al., 2004). The bilateral regions where activation was observed in the published experiments were similar to the brain regions $(-42,16,40$; $53,30,11)$ in our experiment among the Changed Group. After viewing the negative videos, those in the Changed Group were thought to have used induction to make a binary choice.

A recent finding plausibly extends the role of distraction minimisation in a social context when one person's intention is inconsistent with the second person's behaviour (Weissman et al., 2008). BA9 is recruited in tasks that involve the inconsistency of others' intentions. In a previous experiment, subjects were required to view an animation in which a boy followed or did not follow a verbal instruction from a woman standing behind him to touch a blinking dial or a different part of the table. BA9 was recruited when the boy did not follow the woman's instruction (Weissman et al., 2008). In our experiment, a similar region $(-42,16,40)$ was recruited when the subjects accepted the negative information regarding the favoured candidate provided by a rival (and consequently changed their minds). In both experiments, subjects found a "social" situation when viewing contradictory behaviours on the part of two characters in two settings, i.e., animated characters and political figures in campaign advertisements. The characters in both videos were regarded as social creatures, so that the inconsistency in their behaviour (i.e., the boy going against the woman's instruction and the rival's attack on the favoured candidate) may be interpreted as ensuing from their contradictory intentions. The neural correlate was also thought to be capable of distinguishing the inconsistency in a social situation from the inconsistency of a single person's behaviour. The posterior superior temporal sulcus, instead of BA9, was recruited in the task that involved viewing an animated character reaching to grasp a blinking dial (correct or expected) or an empty space (incorrect or unexpected; Pelphrey et al., 2004).

Activation of these regions was observed in the political tasks, regardless of the positive and negative advertisements. The results imply that the Changed Group considered the information in the latest political advertisements to be more relevant.

\section{ACTIVATION DURING THE SECOND POSITIVE ADVERTISEMENTS}

During the second positive advertisements we found activation in the bilateral posterior dorsolateral prefrontal cortices among the Changed groups in both the cola and political tasks. The bilateral dorsolateral prefrontal cortices are also recruited in minimising cross-modal distraction (Weissman et al., 2004), in coordinating between different tasks (Derrfuss et al., 2004) and deciding to gamble with the feedback of varying probabilities of winning (Satterthwaite et al., 2007). The regions activated in the posterior part of the dorsolateral prefrontal cortices in the published works are similar to those activated in the Changed Group during the second positive advertisement sessions for both the cola and the political figures.

For the right anterior dorsolateral prefrontal cortex, however, the activation was observed among the Changed group during the second positive political advertisement, but among the Unchanged Group during the second positive cola session (Table 1). The anterior and posterior dorsolateral prefrontal cortices have been interpreted as being associated with response selection from memory and working memory maintenance, respectively (Duncan and Owen, 2000; Rowe et al., 2000). According to the literature (Wagner et al., 2001), tasks requiring memory selection (i.e., semantic comparisons of three words based on subjective desirability) recruited a similar region in the anterior part of the right dorsolateral prefrontal cortex, where our experiment found a negative correlation between the neural signal change and preference change towards others.

Smaller preference changes after the second positive political advertisements may have resulted from memory selection, whereas larger changes accompanying switching support from one candidate to another may have resulted from memory maintenance. The activation associated with the positive political advertisement may be linked to a form of cognitive control distinct from the one for the negative advertisement, although the social implication of cognitive control has not been specified in its entirety.

\section{COMPLEMENTARY RELATIONSHIP BETWEEN BEHAVIOURAL AND NEUROMETRIC ANALYSIS}

In our experimental context, the Unchanged Group examined the negative information deductively, but the Changed Group 
used induction and considered the newer information to be more relevant, regardless of the negative or positive implication. The neural correlate, however, hinges on the task used in the experiment. More specifically, activation of the medial prefrontal cortex might be associated with preference changes if deductive reasoning supports the validity of the negative information; the activation of the lateral prefrontal cortex might be associated with rejection of the negative message by induction. These neural processes do not necessarily result in a one-to-one correspondence among observed attitudes, choices, and decisions. In this regard, the behavioural data analysis provides important supplementary evidence to the neurometric analysis. For example, greater activation of the medial prefrontal region (medial BA8) was also observed among those with a relatively high preference for the favoured candidate vs. the candidate who was not fovoured before the negative advertisements, and this group did not necessarily overlap with the Unchanged Group. A preference gap before the negative advertisements had a weak, statistically insignificant correlation with a drop in preference for the attacked (originally favoured) candidate after the negative advertisements $(0.1 ; p=0.5392)$. This implies that the activation was related to deductive judgement rather than to the presence or absence of preference changes that demarcated the Changed and Unchanged Groups. Similar to the Unchanged Group, those with a more discriminating preference scaling used a deductive approach to forming judgements. The neural circuitry should be considered linked to a specific form of cognitive control rather than to a specific choice of behaviour, represented by switching or maintaining support.

The additional behavioural data analysis provided evidence that those more detached from the objects (i.e., political candidates) are less susceptible to changes after newer stimuli. An increase (+) and decrease (-) in preference for the (originally) favoured candidate during the negative advertisements were negatively correlated with the preference towards the favoured candidate before the negative advertisements. This change in preference for the (originally) favoured candidate was also negatively correlated with the preference towards the non-favoured candidate before the negative advertisements. These results imply that those who generally reported higher preferences for both were more likely to drop the preference for the favoured candidate after the negative advertisements (and were more likely to change their minds). However, those who originally reported relatively low preferences for both candidates tended to report fewer changes during negative advertisements. Here, the stable preference plausibly resulted from a generally low level of affinity, regardless of preference order, rather than a greater attachment to the favoured candidate. To choose one among others while weighing often conflicting information constitutes an important social capability known as "social intelligence." Experimental psychologists believe that those who are more sensitive to information that potentially reveals a lack of trustworthiness in others tend to maintain once formed trust (Ostrom and Walker, 2003; Yamagishi et al., 1999). This implication is consistent with the observation of fewer preference changes among those who were detached from both candidates. This is also consistent with the neural correlates of deductive reasoning among the Unchanged Group in our experiments.
Alternatively, neural correlates often have implications for understanding attitudes, choices, and decisions in our social lives. Our experiment used videos from a past electoral campaign that was not related to the subjects' immediate political experience, so that stable preferences, such as partisanship, should not have been involved. This is distinguished from a neuropolitical experiment in which the stimulus has immediate political relevance for subjects with clear partisan loyalties, and thus it might explain the activation of the region that is linked to cognitive control rather than to emotional regulation. The activation of the region linked to emotion might result from preservation of deeply rooted preferences relating to partisan ideology and belonging to specific social groups (Kaplan et al., 2007; Knutson et al., 2006; Phelps et al., 2000; Westen et al., 2006).

Comparisons of experimental results obtained during the political and cola sessions suggest curious implications with regard to social behaviour. The same regions were not activated when negative commercial advertisements were viewed. Our results suggest the possibility that commercial advertisements might not be equivalent to political advertisements as social stimuli.

\section{ACTIVATION IN REWARD-RELATED REGIONS}

In neuroeconomics, the reward-related region of the brain is thought to be associated with social preferences that also influence decision making about one's own rewards. The pleasure derived from achieving social motives was regarded as similar to the pleasure ensuing from one's own reward (Fehr and Camerer, 2007). From among the reward-related regions, our experiments found activation in the ventromedial prefrontal cortex (Fehr and Camerer, 2007; Lee, 2008; Loewenstein et al., 2008) among those who changed their preferences after viewing the second positive campaign video.

The ventromedial cortex activated in our study was adjacent to the region recruited in the prior experiments during a binary judgement in opposing contexts, that is, when given and not given formally irrelevant information (i.e., with and without a framing effect) (Deppe et al., 2005a; McClure et al., 2004). Some studies reported that the ventromedial prefrontal cortex was associated with a reward decision under the influence of a specific brand name of goods (Deppe et al., 2005a, b) or with the modulation of emotional rejection to unfair treatments by others at the expense of one's own reward (Koenigs and Tranel, 2007). In contrast, other studies found that it was associated with the exclusive evaluation of one's own rewards when controlling the brand name of goods (McClure et al., 2004) or when not influenced by behavioural feedback, such as punishment or anticipation (Knutson et al., 2001; O'Doherty et al., 2003). An explanation for the opposite results is that different ventromedial prefrontal cortex regions might have been recruited by social stimuli from those associated exclusively with reward consideration, i.e., without interfering with social motives (Harris et al., 2007). However, the region activated in our experiment $(16,61,6:$ BA10) is similar to those activated in the two studies with opposing results (Deppe et al., 2005a; McClure et al., 2004).

An alternative explanation to this contradiction is that the ventromedial prefrontal cortex is commonly recruited by social cognition involving affective judgements (Northoff et al., 2006). Evaluating 
the relationship between stimuli and oneself (i.e., self-relatedness) is a critical component in the evaluation of rewards and social cognition. The evaluation of one's rewards, based on subjective values, is essentially "affective," but an intrinsic reward consideration may or may not be related to consideration of the relationships between oneself and others. A prior study (de Greck et al., 2008) identified an association between part of the ventromedial prefrontal cortex and self-related considerations; this association was observed in addition to those involving other reward-related regions, such as the striatum, thought to be closely linked to social interactions in reward decisions (Lee, 2008). The apparently contradictory results reported in published experiments imply that the neural correlates of self-revaluation might be dissociated from reward-related regions. Our results support this possibility.

\section{METRIC REPRESENTATION OF PREFERENCE AND BEHAVIOUR}

The metric representation of behaviour is prerequisite for closely relating its changes to neural activities. The hypothesized continuity of social preferences with reward consideration enables one to define social decision by externally quantifiable variables, i.e., rewards. We verified the validity of a self-scaled affinity towards others as a metric representation of the brain activities involved in preference changes towards others. As a rating measure of (un)favourable feelings towards presidential candidates, our experiment adopted a self-reported rating method, which was based on a post-task questionnaire. We verified the use of this method by identifying the neural correlates of cognitive control that were tracked by retrospective scaling reported in the posttask questionnaire. This constitutes a promising representation

\section{REFERENCES}

Amodio, D. M., and Frith, C. D. (2006). Meeting of minds: the medial frontal cortex and social cognition. Nat. Rev. Neurosci. 7, 268-277.

Cairns, E., Kenworthy, J., Campbell,A., and Hewstone, M. (2006). The role of ingroup identification, religious group membership and intergroup conflict in moderating in-group and out-group affect. Br. J. Soc. Psychol. 45, 701-716.

Camerer, C. F. (2008). Behavioural game theory. In The New Palgrave Dictionary of Economics, Vol. 1, 2nd edn, S. N. Durlauf and L. E. Blume, eds (New York, Palgrave Macmillan), pp. 444-448.

Canessa, N., Gorini, A., Cappa, S. F., Piattelli-Palmarini, M., Danna, M., Fazio, F., and Perani, D. (2005). The effect of social content on deductive reasoning: an fMRI study. Hum. Brain Mapp. 26, 30-43.

Carpenter, J. (2008). Social preferences. In The New Palgrave Dictionary of Economics, Vol. 7, 2nd edn, S. N. Durlauf and L.E. Blume, eds (New York, Palgrave Macmillan), pp. 651-655.

de Greck, M., Rotte, M., Paus, R., Moritz, D., Thiemann, R., Proesch, U., Bruer, U., Moerth, S., Tempelmann, C., Bogerts, B., and Northoff, G. (2008).
Is our self based on reward? Selfrelatedness recruits neural activity in the reward system. Neuroimage 39 , 2066-2075.

Deppe, M., Schwindt, W., Kramer, J., Kugel, H., Plassmann, H., Kenning, P., and Ringelstein, E. B. (2005a). Evidence for a neural correlate of a framing effect: bias-specific activity in the ventromedial prefrontal cortex during credibility judgments. Brain Res. Bull. 67, 413-421.

Deppe, M., Schwindt, W., Kugel, H., Plassmann, H., and Kenning, P. (2005b). Nonlinear responses within the medial prefrontal cortex reveal when specific implicit information influences economic decision making. J. Neuroimaging 15, 171-182.

Derrfuss,J., Brass, M., and von Cramon, D. Y. (2004). Cognitive control in the posterior frontolateral cortex: evidence from common activations in task coordination, interference control, and working memory. Neuroimage 23, 604-612.

Duncan, J., and Owen, A. M. (2000). Common regions of the human frontal lobe recruited by diverse cognitive demands. Trends Neurosci. 23, 475-483.

Fehr, E., and Camerer, C. F. (2007). Social neuroeconomics: the neural circuitry

of attitudes and might enable the application of psychometricneurometric comparisons to a variety of social behaviours. Our research confirms that the self-rated preference towards others used in our experiment, can be used as subjective values. It thereby proposes an alternative measurement to externally quantifiable variables defined by utility functions in neuroeconomics (Kable and Glimcher, 2007).

Our findings imply that the neurometric analysis requires careful interpretation of the neural data analysis to derive behavioural implications. Although the neurometric analysis helps to find the neural correlates of mental states (Kay et al., 2008), the subtle working of the brain precludes an easy extension of this finding to the neural correlates of behaviour.

\section{ACKNOWLEDGEMENTS}

This study was supported in part by a Grant-in-Aid for Scientific Research on Priority Areas (\#19046001) to J. Kato, I. Kabashima, and K. Kansaku. We thank M. Chun for fruitful discussions and for co-organising an interdisciplinary meeting, "Mind, Brain and Society: Neurocognitive Approaches to the Social Sciences", between neuroscientists and social scientists at Yale University on April 25, 2008, with J. Kato. We are grateful to H. Komiyama and R. Levin who launched the Todai-Yale Initiative that sponsored the symposium and to M. Asashima and G. Joseph who helped our academic exchange fruitful in a variety of ways. We thank T. Kochiyama, T. Shimotomai, D. Salat, K. Sakai, and F. MacDonald for their help. We also thank D. Lee for his continuous encouragement and the two reviewers for improving this manuscript. All trademarks appearing in this article are the property of their respective owners.

of social preferences. Trends Cogn. Sci. $11,419-427$.

Goel, V. (2007). Anatomy of deductive reasoning. Trends Cogn. Sci. 11, 435-441.

Goel, V., and Dolan, R. J. (2004) Differential involvement of left prefrontal cortex in inductive and deductive reasoning. Cognition 93 B109-B121.

Harris, L. T., McClure, S. M., van den Bos, W., Cohen, J. D., and Fiske, S. T. (2007). Regions of the MPFC differentially tuned to social and nonsocial affective evaluation. Cogn. Affect. Behav. Neurosci. 7, 309-316.

Kable, J. W., and Glimcher, P. W. (2007) The neural correlates of subjective value during intertemporal choice. Nat. Neurosci. 10, 1625-1633.

Kaplan,J.T., Freedman,J., and Iacoboni, M. (2007). Us versus them: political attitudes and party affiliation influence neural response to faces of presidential candidates. Neuropsychologia 45 , 55-64.

Katznelson, I., and Weingast, B. R. (2005). Preferences and Situations: Points of Intersection Between Historical and Rational Choice Institutionalism. New York, Russell Sage Foundation.
Kay, K. N., Naselaris, T., Prenger, R. J., and Gallant, J. L. (2008). Identifying natural images from human brain activity. Nature 452, 352-355.

Knutson, B., Adams, C. M., Fong, G. W., and Hommer, D. (2001). Anticipation of increasing monetary reward selectively recruits nucleus accumbens. J. Neurosci. 21, RC159.

Knutson, K. M., Wood, J. N., Spampinato, M. V., and Grafman, J. (2006). Politics on the brain: an MRI investigation. Soc. Neurosci. 1, 25-40.

Koenigs, M., and Tranel, D. (2007). Irrational economic decision-making after ventromedial prefrontal damage: evidence from the ultimatum game. J. Neurosci. 27, 951-956.

Lancaster, J. L., Woldorff, M. G., Parsons, L. M., Liotti, M., Freitas, E. S., Rainey, L., Kochunov, P. V., Nickerson, D., Mikiten, S. A., and Fox, P. T. (2000). Automated Talairach atlas labels for functional brain mapping. Hum. Brain Mapp. 10, 120-131.

Lau, R. R., Sigelman, L., and Rovner, I. B. (2007).The effects of negative political campaigns: a meta-analytic reassessment. J. Politics 69, 1176-1209.

Lee, D. (2008). Game theory and neural basis of social decision making. Nat. Neurosci. 11, 404-409. 
Lieberman, M. D. (2007). Social cognitive neuroscience: a review of core processes. Annu. Rev. Psychol. 58, 259-289.

Loewenstein, G., Rick, S., and Cohen, J. D. (2008). Neuroeconomics. Annu. Rev. Psychol. 59, 647-672.

McClure, S. M., Li, J., Tomlin, D., Cypert, K. S., Montague, L. M., and Montague, P. R. (2004). Neural correlates of behavioral preference for culturally familiar drinks. Neuron 44 , 379-387.

Miller, E. K., and Cohen, J. D. (2001). An integrative theory of prefrontal cortex function. Annu. Rev. Neurosci. 24, 167-202.

Monti, M. M., Osherson, D. N., Martinez, M. J., and Parsons, L. M. (2007). Functional neuroanatomy of deductive inference: a languageindependent distributed network. Neuroimage 37, 1005-1016.

Mueller, D. C. (2003). Public Choice III. Cambridge, Cambridge University Press.

Mutz, D. C., Sniderman, P. M., and Brody, R. A. (1996). Political Persuasion and Attitude Change. Ann Arbor, University of Michigan Press.

Northoff, G., Grimm, S., Boeker, H., Schmidt, C., Bermpohl, F., Heinzel, A., Hell, D., and Boesiger, P. (2006). Affective judgment and beneficial decision making: ventromedial prefrontal activity correlates with performance in the Iowa gambling task. Hum. Brain Mapp. 27, 572-587.
O’Doherty,J.,Critchley,H.,Deichmann, R., and Dolan, R. J. (2003). Dissociating valence of outcome from behavioral control in human orbital and ventral prefrontal cortices. J. Neurosci. 23, 7931-7939.

Oldfield, R. C. (1971). Assessment and analysis of handedness: Edinburgh inventory. Neuropsychologia 9, 97-113.

Ostrom, E., and Walker, J. (2003). Trust and Reciprocity: Interdisciplinary Lessons from Experimental Research. New York, Russell Sage Foundation.

Pelphrey, K. A., Morris, J. P., and McCarthy, G. (2004). Grasping the intentions of others: the perceived intentionality of an action influences activity in the superior temporal sulcus during social perception. J. Cogn. Neurosci. 16, 1706-1716.

Phelps, E. A., O'Connor, K. J., Cunningham, W.A., Funayama, E. S., Gatenby, J. C., Gore, J. C., and Banaji, M. R. (2000). Performance on indirect measures of race evaluation predicts amygdala activation. J. Cogn. Neurosci. 12, 729-738.

Rowe, J. B., Toni, I., Josephs, O., Frackowiak, R. S., and Passingham, R. E. (2000). The prefrontal cortex: response selection or maintenance within working memory? Science 288, 1656-1660.

Satterthwaite, T.D., Green, L., Myerson, J. Parker, J., Ramaratnam, M., and Buckner, R. L. (2007). Dissociable but inter-related systems of cognitive control and reward during decision making: Evidence from pupillometry and event-related fMRI. Neuroimage 37, 1017-1031.

Talairach, J., and Tournoux, P. (1988). CoPlanar Stereotaxic Atlas of the Human Brain. New York, Thieme.

Volz, K. G., Schubotz, R. I., and von Cramon, D. Y. (2004). Why am I unsure? Internal and external attributions of uncertainty dissociated by fMRI. Neuroimage 21, 848-857.

Volz, K. G., Schubotz, R. I., and von Cramon, D. Y. (2005). Variants of uncertainty in decision-making and their neural correlates. Brain Res. Bull. 67, 403-412.

Wagner, A. D., Maril, A., Bjork, R. A., and Schacter, D. L. (2001). Prefrontal contributions to executive control: fMRI evidence for functional distinctions within lateral Prefrontal cortex. Neuroimage 14, 1337-1347.

Weisberg, H. F., and Miller, A. H (1979). Evaluation of the Feeling Thermometer: A Report to the National Election Study Board Based on Data from the 1979 Pilot Survey. Ann Arbor, MI, American National Election Studies.

Weissman, D. H., Perkins, A. S., and Woldorff, M. G. (2008). Cognitive control in social situations: a role for the dorsolateral prefrontal cortex. Neuroimage 40, 955-962.

Weissman, D. H., Warner, L. M., and Woldorff, M. G. (2004). The neural mechanisms for minimizing cross-modal distraction. I. Neurosci. 24, 10941-10949.

Westen, D., Blagov, P. S., Harenski, K. Kilts, C., and Hamann, S. (2006) Neural bases of motivated reasoning: an fMRI study of emotional constraints on partisan political judgment in the 2004 US Presidential election. J. Cogn. Neurosci. 18, 1947-1958.

Yamagishi, T., Kikuchi, M., and Kosugi, M. (1999). Trust, gullibility, and social intelligence. Asian J. Soc. Psychol. 2, 145-161.

Conflict of Interest Statement: The authors declare that the research was conducted in the absence of any commercial or financial relationships that could be construed as a potential conflict of interest.

Received: 05 February 2009; paper pending published: 23 February 2009; accepted: 06 May 2009; published online: 18 May 2009.

Citation: Kato J, Ide H, Kabashima I, Kadota H, Takano K and Kansaku K (2009) Neural correlates of attitude change following positive and negative advertisements. Front. Behav. Neurosci. (2009) 3:6. doi:10.3389/neuro.08.006.2009

Copyright (c) 2009 Kato, Ide, Kabashima, Kadota, Takano and Kansaku. This is an open-access article subject to an exclusive license agreement between the authors and the Frontiers Research Foundation, which permits unrestricted use, distribution, and reproduction in any medium, provided the original authors and source are credited. 